\title{
A Murine Model for Neuropsychiatric Disorders Associated with Group A $\beta$-Hemolytic Streptococcal Infection
}

\author{
Kurt L. Hoffman, Mady Hornig, Kavitha Yaddanapudi, Omar Jabado, and W. Ian Lipkin \\ Greene Infectious Disease Laboratory, Mailman School of Public Health, Columbia University, New York, New York 10032
}

A syndrome of motoric and neuropsychiatric symptoms comprising various elements, including chorea, hyperactivity, tics, emotional lability, and obsessive-compulsive symptoms, can occur in association with group A $\beta$-hemolytic streptococcal (GABHS) infection. We tested the hypothesis that an immune response to GABHS can result in behavioral abnormalities. Female SJL/J mice were immunized and boosted with a GABHS homogenate in Freund's adjuvant, whereas controls received Freund's adjuvant alone. When sera from GABHSimmunized mice were tested for immunoreactivity to mouse brain, a subset was found to be immunoreactive to several brain regions, including deep cerebellar nuclei (DCN), globus pallidus, and thalamus. GABHS-immunized mice having serum immunoreactivity to DCN also had increased IgG deposits in DCN and exhibited increased rearing behavior in open-field and hole-board tests compared with controls and with GABHS-immunized mice lacking serum anti-DCN antibodies. Rearing and ambulatory behavior were correlated with IgG deposits in the DCN and with serum immunoreactivity to GABHS proteins in Western blot. In addition, serum from a GABHS mouse reacted with normal mouse cerebellum in nondenaturing Western blots and immunoprecipitated C4 complement protein and $\alpha-2$ macroglobulin. These results are consistent with the hypothesis that immune response to GABHS can result in motoric and behavioral disturbances and suggest that anti-GABHS antibodies cross-reactive with brain components may play a role in their pathophysiology.

Key words: obsessive-compulsive disorder; PANDAS; group A $\beta$-hemolytic streptococcus; Tourette syndrome; attention-deficit/hyperactivity disorder; autoimmunity

\section{Introduction}

Group A $\beta$-hemolytic streptococcal (GABHS) infection is associated with a spectrum of neurologic and neuropsychiatric disorders, including Sydenham's chorea (SC), obsessive-compulsive disorder (OCD), Tourette sydrome (TS), chronic tic disorder (CTD), and attention-deficit/hyperactivity disorder (ADHD) (Husby et al., 1977; Swedo et al., 1998; Peterson et al., 2000; Muller et al., 2001). There is considerable diagnostic comorbidity among these disorders. A common theme is the concept that dysfunctions in the cortico-striato-thalamo-cortical (CSTC) circuits normally implicated in the integration of emotional, cognitive, and motor functions contribute to their pathogenesis. Volumetric or metabolic abnormalities in the orbital frontal cortex, anterior cingulate cortex, thalamus, caudate, putamen, and globus pallidus have been reported in subjects with SC, OCD, TS, CTD, and ADHD (Sheppard et al., 1999) and decreased volumes

\footnotetext{
Received March 26, 2003; revised Dec. 12, 2003; accepted Dec. 19, 2003.

This work was supported by Tourette Syndrome Association Fellowship Award (K.L.H.), National Institutes of Health Awards MH01608 (M.H.), HD37546 (M.H., W.I.L.), and NS29425 (W.I.L.), and the Ellison Medical Foundation (W.I.L.). We are grateful to Sue Swedo for introducing us to the PANDAS syndrome and for helpful discussions during the course of this project and to Michael Wilson for his gift of antibodies to SNAP-25.

Correspondence should be addressed to W. I. Lipkin, Greene Infectious Disease Laboratory, Mailman School of Public Health, Columbia University, 722 West 168 Street, Room 1801, New York, NY 10032. E-mail: wil2001@columbia.edu.

D01:10.1523/JNEUROSCI.0887-03.2004

Copyright $\odot 2004$ Society for Neuroscience $\quad 0270-6474 / 04 / 241780-12 \$ 15.00 / 0$
}

of posterior cerebellar vermis were reported in subjects with ADHD (Mostofsky et al., 1998; Castellanos et al., 2001).

$\mathrm{SC}$ is a variant of rheumatic fever (RF) attributed to serum anti-GABHS antibodies that cross-react with neurons in the basal ganglia (Husby et al., 1977). OCD, ADHD, tic disorders, emotional lability, hyperactivity, and age-regressed behavior frequently accompany SC (Swedo et al., 1989, 1993; Moore, 1996; Asbahr et al., 1998; Mercadante et al., 2000). Swedo et al. (1998) characterized a subgroup of pediatric subjects with OCD or tic disorders without comorbid SC, the symptom onset of which was associated with GABHS infection; this subgroup was designated with the acronym PANDAS (Pediatric Autoimmune Neuropsychiatric Disorders Associated with Streptococcal Infection). Many PANDAS subjects had comorbid ADHD, affective disorder, and anxiety disorders.

Altered immune processes may play a role in the onset or exacerbation of neuropsychiatric symptoms associated with GABHS infection. Increased serum anti-GABHS antibody titers were associated with a diagnosis of ADHD. In addition, elevated anti-GABHS antibody titers predicted increased putamen and globus pallidus volumes measured with magnetic resonance imaging (MRI) in subjects with ADHD and OCD (Peterson et al., 2000). In PANDAS subjects, increased caudate, putamen, and globus pallidus volumes were interpreted to represent localized brain inflammation (Giedd et al., 2000). An increased proportion of B lymphocytes of PANDAS subjects was positive for the anti- 
gen D8/17, a marker associated with vulnerability to RF (Swedo et al., 1997). Immune-modulating therapies [intravenous Ig (IVIg) and plasmapheresis] ameliorated neuropsychiatric symptoms in PANDAS (Perlmutter et al., 1999). Last, pediatric subjects with OCD had elevated levels of type-1 cytokines in CSF compared with subjects with schizophrenia (Mittleman et al., 1997). These findings are consistent with models wherein GABHS infection or abnormal immune functions are factors in the pathogenesis of a subset of OCD, tic disorders, or ADHD, or where common underlying genetic factors underlie vulnerability to both neuropsychiatric disorders and GABHS infections.

To investigate the mechanisms by which immune response to GABHS antigens might alter neuronal function and cause behavioral disturbances, we established a murine model on the basis of experimental immunization with a homogenate prepared from GABHS. Experiments reported here test the hypothesis that an immune response to GABHS can lead to behavioral abnormalities reminiscent of those reported in PANDAS.

\section{Materials and Methods}

\section{GABHS homogenate (immunogen)}

Blood agar plates were inoculated with Streptococcus pyogenes, group A type 6 (12348; American Type Culture Collection, Manassas, VA), and incubated overnight at $37^{\circ} \mathrm{C}$. Brain-heart infusion broth (Difco, Kansas City, MO) was inoculated with colonies that displayed clear $\beta$-hemolytic activity on blood agar. After incubation at $37^{\circ} \mathrm{C}$ for $96 \mathrm{hr}$, bacteria were collected by centrifugation and resuspended in sterile PBS. To prepare GABHS homogenate, bacteria were pelleted, rinsed with PBS, pelleted again, and resuspended in water. Zirconia-silica beads $(0.1 \mathrm{~mm}$; BioSpec Products, Bartlesville, OK) were added, and the suspension was vortexed for $12 \mathrm{~min}$ at $4^{\circ} \mathrm{C}$. Supernatant was collected after the beads settled out of the suspension. Beads were rinsed with water, and rinse water was added to the supernatant. After beads were removed from the supernatant by centrifugation at $6000 \mathrm{rpm}$, the supernatant (hereafter designated GABHS homogenate) was collected and stored at $-70^{\circ} \mathrm{C}$. GABHS homogenate was incubated with blood agar plates to verify that it contained no viable bacteria.

\section{Animals and immunization protocol}

All housing, care, experimental procedures, and killing of mice were performed according to Association for Assessment and Accreditation of Laboratory Animal Care guidelines and approved by the Institutional Animal Care and Use Committee at University of California Irvine before initiation. Five-week-old female SJL/J mice (The Jackson Laboratory, Bar Harbor, ME) were housed under fluorescent lighting set to a 12 $\mathrm{hr}$ light/dark schedule. Primary immunization was performed when the mice were 6 weeks of age. Complete Freund's adjuvant (CFA) and incomplete Freund's adjuvant (IFA) were obtained from Sigma-Aldrich (St. Louis, MO). Each mouse in the GABHS group was immunized subcutaneously with $\sim 125 \mu \mathrm{l}$ of 1:1 emulsion of CFA:PBS containing $2.5 \mu \mathrm{l}$ of GABHS homogenate. Control mice were immunized with $\sim 125 \mu \mathrm{l}$ of CFA:PBS alone. Boosts were given at 4 or 6 week intervals and consisted of $\sim 125 \mu \mathrm{l}$ of $1: 1$ emulsion of IFA:PBS containing $2.5 \mu \mathrm{l}$ of GABHS homogenate (for GABHS mice) or $\sim 125 \mu$ l of IFA:PBS alone (control mice). Blood ( $\sim 50-350 \mu \mathrm{l})$ was collected by tail bleed $14 \mathrm{~d}$ after the primary immunization and after each boost. After clotting and centrifugation at low speed, serum was collected and stored at $-70^{\circ} \mathrm{C}$. Animals examined for brain IgG deposits were killed 3 weeks after the third boost.

Two sets of mice were immunized. The first set $(n=7$ GABHS; $n=7$ controls) was immunized at 6 weeks of age and then boosted three times at 6 week intervals. The second set ( $n=16$ GABHS; $n=13$ controls) was immunized at 6 weeks of age and boosted three times at 4 week intervals. Sera were collected 2 weeks after each boost. Sera from boosts 1, 2, and 3 were screened for immunoreactivity to brain tissue.

\section{Behavioral testing}

An automated system (Tru Scan testing arenas and Tru Scan 99 software; Coulbourn Instruments, Allentown, PA) was used to quantitate move time (total time in movement), distance (sum of vectored coordinate displacements), ambulatory distance (measurement of locomotion), center time (time in center of arena), dark time (time in a darkened plastic box, having a small hole for entry and exit that was placed in the arena), rearing count (the number of times the mouse stands upright), and exploratory nose pokes into a hole board (total number of times the mouse inserts its snout into holes cut into the false floor of a hole board).

Behavior was tested during two trials. Trial 1 began $2 \mathrm{~d}$ after the boost 2 blood draw, and trial 2 began $4 \mathrm{~d}$ after boost 3 blood draw. For each trial, three different behavioral tests were performed in the following sequence: dark box, open field, and hole board. The dark-box test was used to assess anxiety behavior, in which increased preference for the darkened half of an open field indicated increased anxiety. Open-field test provided an overall indication of behavioral response to a novel open environment (e.g., behavioral inhibition or activation when confronted with unfamiliar surroundings) and exploratory strategies (e.g., ambulatory distance, center time, rearing). The number of nose pokes into a hole board reflected exploratory behavior.

On the morning of the test (8:00 to 10:00 A.M.), mice were moved from the vivarium to a separate behavioral testing room, where they remained until the testing for that day was complete. Tests were performed from 1:00 to 6:00 P.M. The dark-box test was administered first ( 2 or $4 \mathrm{~d}$ after blood draw for trial 1 or trial 2, respectively), followed by the open-field test ( 3 or $2 \mathrm{~d}$ after dark box for trial 1 or trial 2 , respectively) and the hole-board test ( 2 or $1 \mathrm{~d}$ after open field for trial 1 or trial 2 , respectively). The testing arena was illuminated with a 75 watt incandescent bulb affixed $\sim 18$ inches above the floor of the arena. Pairs of mice ( 1 control, 1 GABHS) were tested simultaneously in separate arenas. Before placement in testing arenas, individual mice were placed into a $500 \mathrm{ml}$ glass beaker for $1 \mathrm{~min}$ to ensure a similar state of behavioral activation. For dark-box tests, mice were placed in the lit side of the arena, near the opening to the dark box. For open-field tests, mice were placed in the center of the arena. For hole-board tests, mice were placed in one of the corners, facing the walls. Test recording began immediately after the mouse was placed in the arena. The duration of the dark-box test was $5 \mathrm{~min}$; the open-field and hole-board tests were $10 \mathrm{~min}$ each.

\section{Immunohistochemistry}

$\operatorname{IgG}$ and CD45. Mice were anesthetized with $\mathrm{CO}_{2}$ and then decapitated. Brains were placed into ice-cold PBS, sectioned in the coronal plane at 3 $\mathrm{mm}$ intervals, and immersed overnight in $30 \%$ sucrose $/ \mathrm{PBS}$ at $4^{\circ} \mathrm{C}$. Brain slices were then quick frozen at $-20^{\circ} \mathrm{C}$ in Tissue-Tek OCT compound (Sakura Finetek, Torrance, CA). Cryostat sections ( $14 \mu \mathrm{M})$ were air-dried onto slides at $37^{\circ} \mathrm{C}$. Horseradish peroxidase (HRP)-conjugated goat antimouse IgG was obtained from Sigma-Aldrich. Biotin-conjugated rat anti-mouse CD45 antibody was obtained from PharMingen (San Diego, CA). Sections on slides were fixed in $4 \%$ paraformaldehyde/PBS at room temperature for $6 \mathrm{~min}$ (mouse sera immunolabeling and visualization of IgG deposits in the brain) or $20 \mathrm{~min}$ (CD45 immunolabeling) and then rinsed $5 \mathrm{~min}$ in PBS. After fixation, sections to be immunolabeled with mouse sera were preincubated for $30 \mathrm{~min}$ in immunobuffer $(4 \times$ concentrated PBS, containing 10\% FBS), followed by overnight incubation in the primary antibody solution (1:200 dilution of mouse serum in immunobuffer) at $4^{\circ} \mathrm{C}$. After rinsing for $30 \mathrm{~min}$ in immunobuffer, sections were incubated for $4 \mathrm{hr}$ in immunobuffer containing secondary antibody (HRP-conjugated goat anti-mouse IgG). Sections were rinsed for $30 \mathrm{~min}$ in immunobuffer, developed with diaminobenzidine (DAB) solution (Vector Laboratories, Burlingame, CA), dehydrated in ethanol, cleared with Americlear clearing solvent (Allegiance Healthcare, McGaw Park, IL), and mounted in Permount (Fisher Scientific, Pittsburgh, PA). For visualization of IgG deposits, fixed sections were incubated in HRPconjugated goat anti-mouse IgG (1:300, in immunobuffer) overnight at $4^{\circ} \mathrm{C}$. The following day, sections were rinsed and developed as described above. For anti-CD45 immunolabeling, fixed sections were immersed in $\sim 95^{\circ} \mathrm{C}$ citrate buffer, microwaved for $30 \mathrm{sec}$, and allowed to remain in the hot buffer for $2 \mathrm{~min}$. The sections were then incubated in immu- 
nobuffer containing $0.01 \%$ detergent (Triton X-100) for $1 \mathrm{hr}$, rinsed 15 $\mathrm{min}$ in PBS, and incubated in biotin-conjugated rat anti-mouse CD45overnight at $4^{\circ} \mathrm{C}$. The following day, slides were rinsed with immunobuffer and developed with Vector Elite $\mathrm{ABC}$ kit and $\mathrm{DAB}$ solution (Vector Laboratories).

To determine significant correlations between IgG deposits in the deep cerebellar nuclei (DCN) and behavioral phenotype, cerebellar sections from the 10 control and 10 GABHS that underwent behavioral testing were immunolabeled for detection of IgG deposits. The slides were coded for blinded analysis and ranked in ascending order from least (having a rank score of 1) to greatest (having a rank score of 20) anti-IgG immunolabeling in the DCN. For rank scoring of IgG deposits in the DCN, IgG immunolabeling in the central portion of the anterior interposed nucleus was examined, except in one case in which this region was not present in the section; in this case, the posterior interposed nucleus was examined.

GABHS antisera and synaptosomal associated protein of $25 \mathrm{kDa} . \mathrm{CO}_{2}$ anesthetized normal adult female SJL mice were perfused through the left ventricle using ice-cold $4 \%$ paraformaldehyde in $0.1 \mathrm{M}$ phosphate buffer, $\mathrm{pH}$ 7.4. Brains were removed, postfixed in the same solution overnight at $4^{\circ} \mathrm{C}$ and cryoprotected in $30 \%$ sucrose/PBS for $36 \mathrm{hr}$ at $4^{\circ} \mathrm{C}$. Cryostat sections $(14 \mu \mathrm{M})$ were collected on slides, permeabilized with $0.1 \%$ Triton X-100 for $30 \mathrm{~min}$, and then blocked for $1 \mathrm{hr}$ in PBS with $10 \%$ normal goat serum (NGS; Sigma). Sections were incubated overnight with control or GABHS mouse sera diluted 1:200 with 1\% NGS in PBS. Rabbit polyclonal antisera to synaptosomal associated protein of $25 \mathrm{kDa}$ (SNAP25) (1:500; gift from Michael Wilson, University of New Mexico, Albuquerque, NM) was used as a synaptic marker; preimmune rabbit sera was used as a control. Sections were incubated for $30 \mathrm{~min}$ with secondary antibodies [goat anti-mouse and rabbit IgG tetramethylrhodamine isothiocyanate (TRITC)/FITC, 1:200 in PBS]. The sections were dehydrated serially in increasing concentrations of ethanol, incubated for $20 \mathrm{~min}$ with Hoechst nuclear stain (Sigma) diluted in 95\% ethanol, and then mounted with Permount (Fisher Scientific). Images were captured with a Nikon (Tokyo, Japan) E600 microscope with Nikon Spot software.

Preabsorption of anti-brain immunoreactivity with GABHS homogenate. A 1:200 dilution of mouse immune serum in $250 \mu \mathrm{l}$ of immunobuffer was incubated in suspension with $80 \mu \mathrm{l}$ of GABHS homogenate overnight at $4^{\circ} \mathrm{C}$ in a tumbler. After pelleting of homogenate by centrifugation, the supernatant (antibody solution) was used immediately for immunohistochemistry. As a control for specificity of the preabsorption effect, a separate aliquot of each mouse immune serum was treated similarly (dilution, overnight tumbling at $4^{\circ} \mathrm{C}$, centrifugation) with the exception of incubation with homogenate.

\section{Reactivity of mouse sera to Western blotted GABHS proteins}

To prepare GABHS protein extract, GABHS homogenate was diluted 1:1 in $0.2 \mathrm{M}$ Tris, $\mathrm{pH} 6.8$, containing $4 \% \mathrm{SDS}$, incubated at $100^{\circ} \mathrm{C}$ for $10 \mathrm{~min}$, and centrifuged at 15,000 rpm for $15 \mathrm{~min}$ to pellet the insoluble material. The resulting supernatant (GABHS extract) was collected and stored at $-70^{\circ} \mathrm{C}$. Proteins in GABHS extract were fractionated by SDS-PAGE (Laemmli and Favre, 1973) and transferred to nitrocellulose using a semidry blotting apparatus.

To determine the immunoreactivity of individual mouse sera to blotted GABHS proteins, strips were cut from GABHS protein blot and incubated for $30 \mathrm{~min}$ in blocking buffer [Tris-buffered saline containing $0.05 \%$ Tween 20 (detergent) and $0.5 \%$ dried milk powder] at room temperature. The strips were then placed in individual wells, each containing diluted serum from a single mouse. Sera collected from mice $2 \mathrm{~d}$ before trial 1 behavioral tests were diluted to 1:250 or 1:2500 with blocking buffer. Strips were incubated overnight at $4^{\circ} \mathrm{C}$ and then rinsed the following day at room temperature for $30 \mathrm{~min}$, with three changes of Trisbuffered saline containing $0.05 \%$ Tween 20 . The strips were incubated for $4 \mathrm{hr}$ at room temperature in secondary antibody solution (HRPconjugated goat anti-mouse IgG, 1:1000 in blocking buffer). The strips were again rinsed as above and developed with Immunopure 3,3',5,5' tetramethylbenzidine (TMB) (Pierce, Rockford, IL) solution $(3 \mathrm{mg} / \mathrm{ml}$
Immunopure TMB in EtOH, diluted 1:10 in Tris-buffered saline, with $0.1 \% \mathrm{H}_{2} \mathrm{O}_{2}$ ). GABHS polypeptides to which sera were immunoreactive were visible on the GABHS Western blot as blue bands. For strips incubated in serum diluted to 1:2500, the number of bands visible on each strip was counted and provided a quantitative measure (the anti-GABHS immunoreactivity index) of serum immunoreactivity to GABHS polypeptides. The anti-GABHS immunoreactivity index was used to test for correlations between serum anti-GABHS antibody response and specific behavioral variables.

\section{Nondenaturing Western blots and immunoprecipitation}

Normal SJL mouse frontal cortex, striatum, and cerebellum were dissected and then homogenized with a Dounce tissue homogenizer (Wheaton Scientific, Millville, NJ) in PBS. Five micrograms of homogenate was resuspended in native protein-loading buffer ( $10 \%$ glycerol, 0.1 м Tris, pH 6.8, bromophenol blue). Proteins were size-fractionated by PAGE in a 10 or $12 \%$ gel and then transferred to nitrocellulose membranes (Bio-Rad, Hercules, CA). Membranes were blocked with $10 \%$ nonfat milk in PBS for $1 \mathrm{hr}$ and then incubated for $1 \mathrm{hr}$ with immune sera of a single mouse (diluted 1:500 with $1 \%$ nonfat milk in PBS). After washing with $0.1 \%$ Tween 20 in PBS, the membranes were incubated with HRP-conjugated, rabbit anti-mouse IgG as secondary antibody (Bio-Rad), diluted 1:2000 in 1\% nonfat milk in PBS. Antibody binding was visualized with ECL Plus Western blotting detection reagent (Amersham Biosciences, Arlington Heights, IL).

Immunoprecipitations (IPs) were pursued under nondenaturing conditions. Because of the uncertainty of the antibody isotype, protein A and protein $\mathrm{G}$ beads (Sigma) were both used for precipitation in a buffer composed of $25 \mathrm{~mm}$ HEPES, $137 \mathrm{~mm} \mathrm{NaCl}, 1 \mathrm{~mm} \mathrm{MgCl}_{2}, 1 \%$ Triton $\mathrm{X}-100,1 \mathrm{~mm}$ sodium orthovanadate, $1 \mathrm{~mm}$ phenylmethylsulfonyl fluoride, $50 \mathrm{~mm}$ sodium fluoride, $10 \mu \mathrm{g} / \mathrm{ml}$ aprotinin, and $10 \mu \mathrm{g} / \mathrm{ml}$ leupeptin (IP buffer). All procedures were conducted on ice; incubations at $4^{\circ} \mathrm{C}$ were continuously mixed by rotation. Mouse immunoglobulins were bound to $50 \mu \mathrm{l}$ of protein A-G by incubation in IP buffer for $1 \mathrm{hr}$. The beads were then added to $1 \mathrm{mg}$ of brain homogenates, resuspended in buffer, and incubated for $1 \mathrm{hr}$. Ten microliters of normal mouse sera or GABHS sera was added to precleared supernatant and incubated overnight. Fifty microliters of fresh protein $A-G$ beads was added to the supernatant and incubated for $4 \mathrm{hr}$. Beads were washed five times with 1 $\mathrm{ml}$ of IP buffer. Twenty microliters of SDS-loading buffer was added to the beads, and proteins were eluted by boiling for $5 \mathrm{~min}$. Proteins were size-fractionated by $10 \%$ SDS-PAGE and visualized by incubation with $50 \mathrm{ml}$ of SYPRO Ruby Protein gel stain overnight (Molecular Probes, Eugene, OR). Unique bands were excised and subjected to liquid chromatography/mass spectrometry/mass spectrometry (LC/MS/MS) analysis. Briefly, gel fragments were digested with endoproteinase Lys-C and trypsin (Roche Molecular Biochemicals, Indianapolis, IN). Peptides were extracted with $50 \%$ acetonitrile $/ 2 \%$ trifluoroacetic acid and then reduced in volume to $10 \mu$ l. Mass spectrometry was performed with a Micromass Q-Tof hybrid quadruple/time of flight mass spectrometer with a nanoelectrospray source. The processed files were submitted to a MASCOT search (Matrix Science, London, UK).

\section{Statistical analysis}

Categorical data were analyzed using $\chi^{2}$ test (Glass and Hopkins, 1996). Statview v.5.0.1 software (SAS Institute, Cary, NC) was used for all other statistical analyses. Group comparisons were done using ANOVA; when appropriate, Fisher's PLSD was used for post hoc comparisons. KruskalWallis and Mann-Whitney $U$ tests were used for nonparametric group comparisons. Correlational analyses were done using $Z$ test followed by Fisher's $r$ to $z$ transformation (parametric) or Spearman rank correlation (nonparametric). For all tests, statistical significance was assumed where $p<0.05$.

\section{Results}

Anti-brain immunoreactivity of sera from GABHS- and control-immunized mice

Sera obtained from GABHS mice were screened for the presence of brain cross-reactive antibodies by immunoperoxidase and in- 

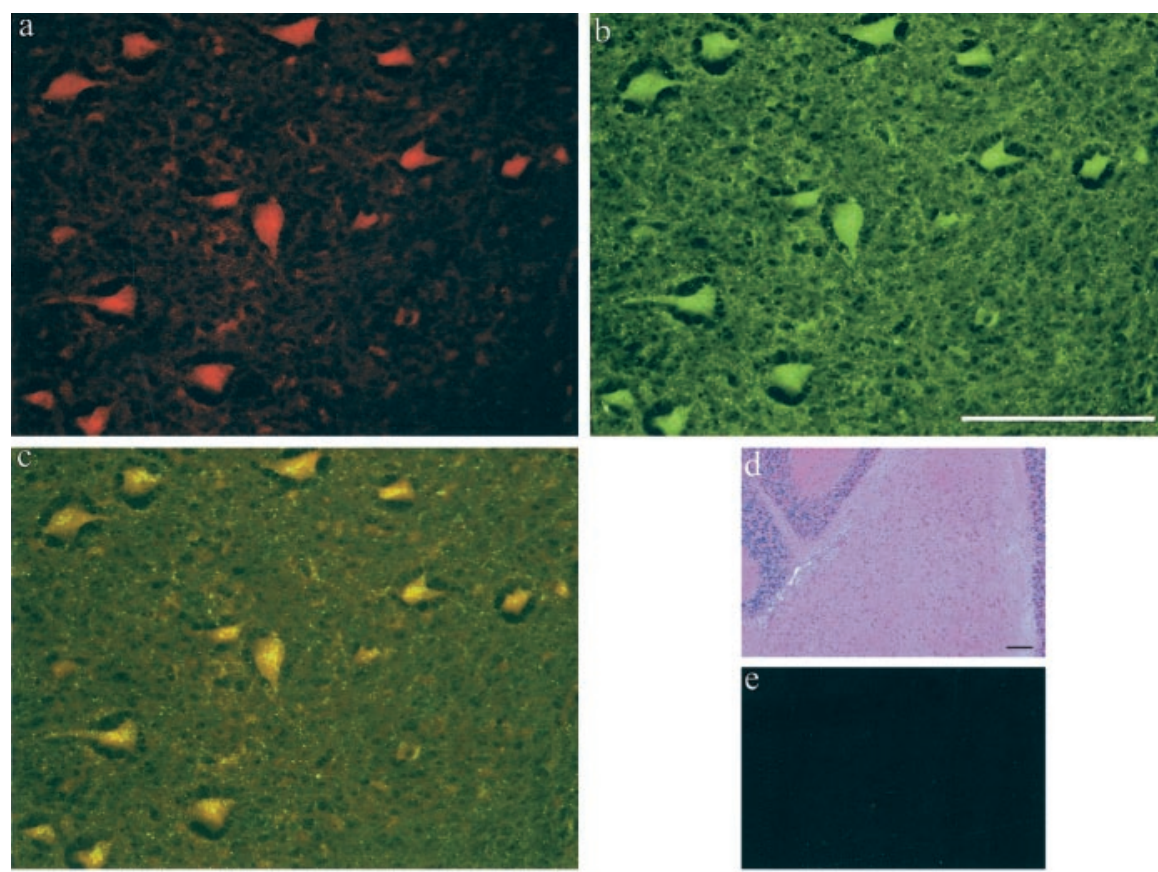

Figure 1. GABHS mouse sera binds specifically to cells in the DCN and colocalizes with the synaptic marker SNAP-25. a, GABHS mouse serum (TRITC) at 40×. b, Rabbit anti-SNAP-25 (FITC) at 40×. c, Combined FITC and TRITC image, punctate SNAP25 staining localizes to GABHS mouse sera reactive cell bodies. $d$, Hematoxylin and eosin at $10 \times . e$, Normal mouse sera at $40 \times$. Scale bars, $100 \mu \mathrm{m}$.

direct immunofluorescence microscopy using sections of normalSJL mouse brain. GABHS mouse serum labeled cell bodies of neurons in DCN. Control sera obtained from mice treated with CFA:IFA did not react with sections of brain tissue. Doublelabeling experiments using GABHS immune sera and antibodies to the synaptic marker SNAP-25 revealed colocalization in DCN (Fig. 1). Immunoreactivity to the DCN was first detected in serum collected after the second boost. Sera were less intensely immunoreactive to several other brain regions including lateral hypothalamus, globus pallidus, reticular thalamic nucleus, superior and inferior colliculus, deep mesencephalic nuclei, pontine nuclei, tegmental nuclei, periolivary nucleus, and several other brainstem motor and sensory nuclei (data not shown).

To assess whether anti-DCN immunoreactivity in GABHS mice was attributable to cross-reactivity with GABHS epitopes present in the original immunogen, sera were preabsorbed with GABHS homogenate before application to tissue sections. Preabsorption of GABHS sera with GABHS homogenate removed the majority of the punctate anti-DCN immunoreactivity (Fig. 2). Control sera immunoreactivity to DCN was not preabsorbed by GABHS homogenate.

\section{IgG deposits in the brain of GABHS mice}

The presence of IgG deposits in the DCN of control $(n=10)$ and GABHS $(n=10)$ mice was assessed by anti-IgG immunohistochemistry. In GABHS mice, anti-IgG immunolabeling in DCN (Fig. 3) was intense in regions adjacent to capillaries. In many areas, anti-IgG label was punctate. In the control mice, anti-IgG label was less pronounced and appeared to be contained within blood vessels (Fig. 3b).

To determine the relationship between GABHS immunization, serum anti-DCN antibodies, and IgG deposits in the DCN, brain tissue sections immunolabeled with anti-IgG were examined by an observer blind to experimental treatment. A rank score (ranging from 1 to 20) was assigned according to the intensity of DCN antiIgG immunoreactivity, providing a quantitative measure of IgG deposits in the DCN. Mann-Whitney $U$ tests showed a significant effect of GABHS immunization on rank score for IgG deposits in the DCN ( $p=0.0032$; mean rank scores: GABHS, 14.4; control, 6.6). The GABHS group was split into subgroups on the basis of the presence $[\operatorname{anti}-\mathrm{DCN}(+), n=6$ ] or absence $[\operatorname{anti}-\operatorname{DCN}(-), n=4]$ of serum anti-DCN antibodies. Comparison of these two subgroups to controls using the Kruskal-Wallis test showed a significant effect of group on rank score for IgG deposits in the DCN $[p=0.006$; mean rank scores for IgG deposits: serum anti$\mathrm{DCN}(+), \quad 16.2$; serum anti-DCN $(-)$, 11.7; control, 6.6]. Rank scores for IgG deposits were significantly greater in serum anti-DCN $(+)$ group compared with control [Mann-Whitney $U$ test; $p=0.0024$; mean rank scores for IgG deposits: serum anti-DCN $(+)$, 13.2; control, 5.7]. Rank scores for IgG deposits in serum anti$\mathrm{DCN}(-)$ mice were intermediate to control and serum anti-DCN $(+)$ groups and did not differ significantly from either control or serum anti-DCN $(+)$ groups (Mann-Whitney $U$ test; data not shown). These results indicate that IgG deposits in the DCN are associated with GABHS immunization and suggest that serum anti-DCN antibodies may be associated with increased IgG deposits in the DCN.

To determine whether the presence of IgG reflected transfer from the vascular compartment or local synthesis, sections were next examined using anti-CD45 antisera for detection of lymphocytes. CD45 cell labeling in the cerebellum was similar in GABHS and control mice. Furthermore, CD45 labeling in GABHS mice did not vary as a function of the presence of parenchymal IgG deposits or the strength of signal associated with these deposits. Together, these results support the hypothesis that immunization with GABHS can lead to the production of crossreactive antibodies that bind to brain in vivo.

\section{Behavioral analysis of GABHS mice}

GABHS $(n=10)$ and control $(n=10)$ mice did not differ in assays of dark-box time, center time, rearing, or total nose pokes in either trial 1 (Fig. 4) or trial 2 (data not shown). However, GABHS mice showed decreased ambulation during the trial 1 open-field test (ANOVA; $F=5.338 ; p=0.0329$ ) (Fig. $4 c$ ), but correction for the multiple comparisons performed across groups for variables in the open-field test (center time and rearing counts in addition to ambulatory distance) showed these differences to no longer be significant (Bonferonni/Dunn; $p=n s$ ). These differences in open-field ambulation were not present in trial 2, and repeated measures ANOVA did not support a significant effect of group on ambulatory distance across trials 1 and 2 



Figure 2. Anti-DCN immunoreactivity can be preabsorbed by incubation with GABHS homogenate. Diluted GABHS-immune serum (1:200) was either applied to tissue without previous preabsorption or preincubated with GABHS homogenate before application to tissue sections. Serum anti-DCN immunoreactivity was visualized with DAB as described in Materials and Methods. Preabsorption with GABHS homogenate significantly reduced anti-DCN immunoreactivity. $a, \mathrm{DCN}$ tissue incubated in serum from a GABHS mouse. Arrows denote several punctate, immunolabeled structures. $b, D C N$ tissue incubated with GABHS-preabsorbed serum from the same GABHS mouse. Scale bar, $50 \mu \mathrm{m}$.

for any of the behavioral tests. It is possible that the decreased ambulation observed in GABHS mice during trial 1 open field was attributable to behavioral inhibition in response to novel surroundings. In support of this hypothesis, the mean ambulatory distance for all three behavioral tests was increased in all groups in trial 2 compared with trial 1 . These data are also consistent with the alternative explanation that there were differences in cytokine-associated, postimmunization sickness behavior, given the shorter $2 \mathrm{~d}$ interval between boost 2 and trial 1 testing, as compared with the $4 \mathrm{~d}$ interval between boost 3 and trial 2 testing. Repeated measures ANOVA showed significant effects of trial on ambulatory distance across trials 1 and 2 for the dark box $(F=4.778 ; p=0.0431)$ and hole board $(F=8.661 ; p=$ $0.0096)$ tests. A trend toward an effect of trial on ambulatory distance $(F=3.098 ; p=0.0954)$ was observed across trials 1 and 2 open-field tests. However, there were no significant group $\times$ trial interaction effects on ambulatory distance for any of the three behavioral tests.

To investigate whether behavioral abnormalities were associated with the presence of serum anti-DCN IgG, the GABHS group was split into anti-DCN $(+)$ and anti- $\mathrm{DCN}(-)$ subgroups ( $n=6$ and $n=4$, respectively). ANOVA revealed significant effects of group on rearing count in trial 1 during the open-field test $(F=5.153 ; p=0.0178)$ and hole-board test $(F=7.731 ; p=$ $0.0045)$. A trend toward an effect of group on rearing count was observed in trial 1 dark-box test $(F=3.051 ; p=0.0737)$. Post hoc Fisher's PLSD confirmed the significantly increased rearing behavior in the anti-DCN $(+)$ group compared with both the control and anti-DCN(-) groups in trial 1 open-field and holeboard tests (Fig. 5). No group differences were observed in the time spent in dark box or in the total number of nose pokes into the hole board. Repeated measures ANOVA showed a significant effect of group on rearing count across trial 1 and 2 open-field tests $(F=4.674 ; p=0.0241)$. Post hoc Fisher's PLSD confirmed increased rearing in the anti-DCN $(+)$ group compared with both the control $(p=0.0042)$ and anti-DCN $(-)(p=0.0014)$ groups. Significant effects of group on rearing count were also present across trial 1 and 2 dark-box $(F=4.450 ; p=0.0279)$ and hole-board $(F=7.378$; $p=0.0054)$ tests. Fisher's PLSD con-



Figure 3. Parenchymal and pericapillary lgG deposition is increased in the DCN of GABHS mice having serum anti-DCN immunoreactivity. Tissue sections from DCN of GABHS and control mice were incubated in peroxidase-conjugated anti-mouse lgG. Anti-IgG binding to DCN was visualized using DAB. Anti-IgG immunoreactivity was increased in the DCN parenchyma of GABHS mice previously determined to have serum anti-DCN immunoreactivity. $a$, Section from the DCN of a GABHS-immune mouse that had serum anti-DCN immunoreactivity. Arrowheads mark the top boundary of a single capillary. Anti-IgG immunoreactivity was particularly intense in pericapillary areas and was in a punctate pattern (arrows). $b$, Section from the DCN of a control mouse. Arrowheads mark the top boundary of a single capillary similar to the one shown in $a$. Note the relative lack of pericapillary immunostaining and the absence of punctate immunostaining compared with $a$. Scale bar, $50 \mu \mathrm{m}$.

firmed the significantly increased rearing count across trials 1 and 2 in anti-DCN $(+)$ group compared with control (dark box, $p=$ 0.0039 ; hole board, $p=0.0019$ ) and with anti-DCN $(-)$ groups (dark box, $p=0.0016$; hole board, $p<0.0001$ ). There was a significant effect of trial on rearing count in the dark-box test $(F=10.924 ; p=0.0042)$, with decreased rearing count in trial 2 compared with trial 1 . Rearing count did not vary between trials for open-field or hole-board tests, nor were there significant group $\times$ trial effects on rearing count in any of the tests.

When control, anti-DCN $(+)$, and anti-DCN $(-)$ groups were compared using ANOVA, there were no significant effects of group on ambulatory distance or center time for trial 1 open-field and hole-board tests. These observations suggested that rearing count increased independently of ambulatory distance and center time in anti-DCN $(+)$ mice and were consistent with increased rearing behavior reflecting repetitive or compulsive-like behavior.

Rearing behavior of control mice did not differ with serum immunoreactivity to DCN. For trial 1 open-field test, the mean rearing counts for control mice having and lacking serum immunoreactivity to DCN were $59 \pm 10$ and $52 \pm 46 \mathrm{SD}$, respectively. For comparison, the mean rearing count for GABHS immunized mice having serum anti-DCN immunoreactivity was $98 \pm 25 \mathrm{SD}$.

\section{Correlates of rearing behavior in GABHS and control mice}

Significant correlations between rearing behavior and other behavioral variables were assessed in GABHS and control mice using a $Z$ test followed by Fisher's $r$ to $z$ transformation. Rearing count in both control and GABHS mice was highly correlated with center time in the open-field test and with ambulatory distance in all three tests (Table 1). There were no correlations between rearing count and either dark-box time or total number of nose pokes into the hole board. The observation that rearing count was positively correlated with ambulatory distance and center time, but not with dark-box time or nose pokes, is consistent with rearing behavior as a component of ambulation in a 

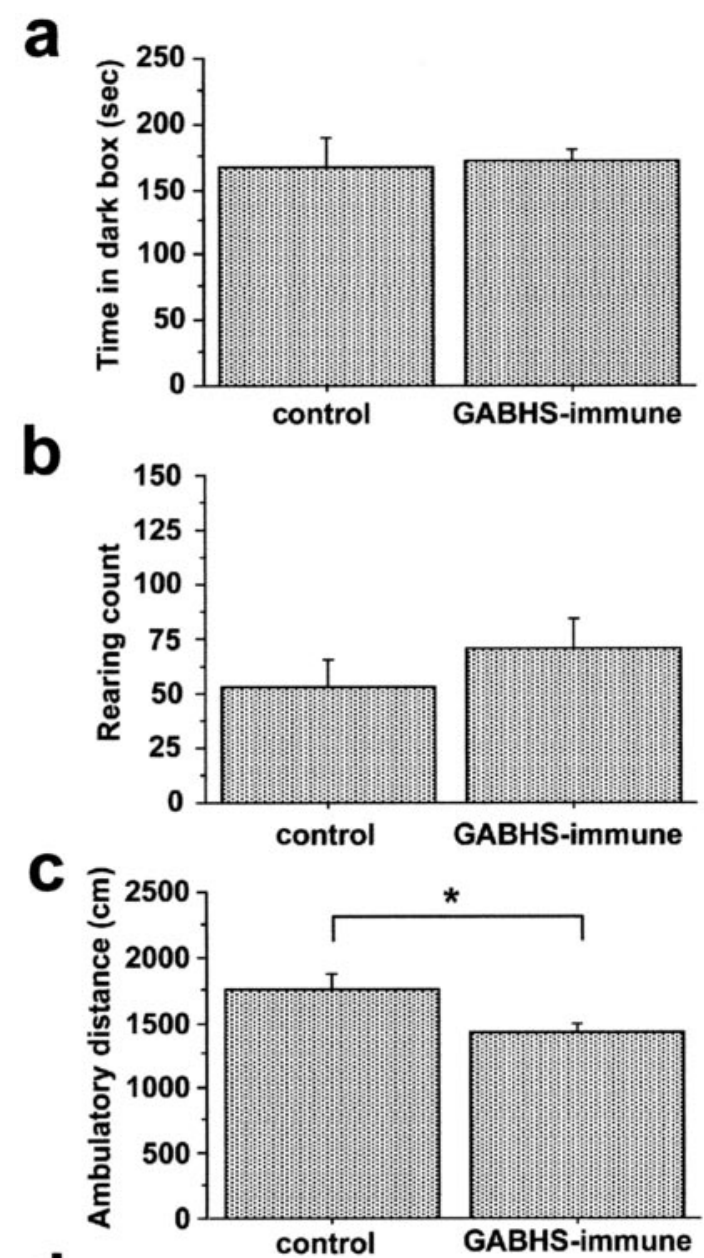

d

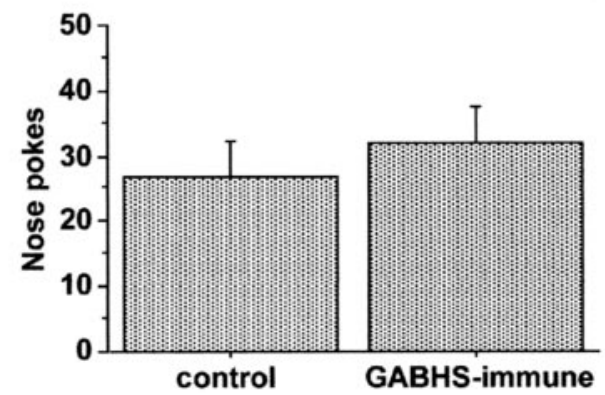

Figure 4. Open-field ambulation of GABHS mice is decreased compared with control. Behaviors during dark-box, open-field, and hole-board tests are shown. $a$, Time spent in darkened half of arena during dark-box test. $b$, Rearing count in open field. $c$, Ambulatory distance in open field. $d$, Total number of exploratory nose pokes into a hole board. Ambulatory distance was significantly decreased in the GABHS-immunized group compared with control (ANOVA; $F=$ 5.338; ${ }^{*} p=0.0329$ ). Error bars indicate SE.

novel open space (reflecting spatial orientation behavior), rather than anxiety or general exploratory behavior.

\section{Behavioral correlates of brain IgG deposits in GABHS and} control mice

We reasoned that if cross-reactive anti-GABHS antibodies altered behavior by binding to brain targets, rearing and ambulation measurements might be correlated with IgG deposits in brain. To test this hypothesis, raw behavioral data were converted to ranked data. Spearman's rank correlation test was used to test for correlation between the rank scores of DCN IgG deposits and
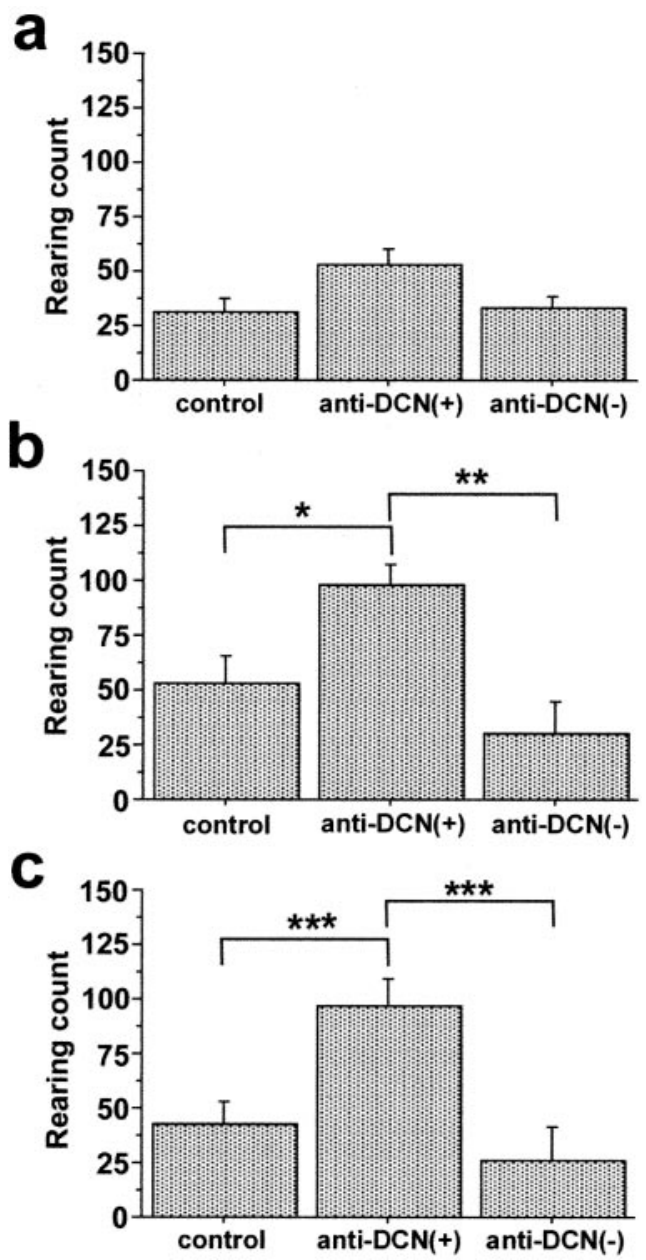

Figure 5. Rearing behavior is increased in GABHS-immunized mice having serum immunoreactivity to DCN. $a-c$, Rearing count during dark-box test ( $a$ ), open-field test $(b)$, and holeboard test $(c)$ for trial 1. Group differences in rearing were significant for open-field (ANOVA; $F=5.153 ; p=0.0178)$ and hole-board $(F=7.731 ; p=0.0045)$ tests but not for dark-box test. In open-field and hole-board tests, rearing count in GABHS mice having serum anti-DCN immunoreactivity [anti-DCN(+)] was significantly greater than for control mice and for mice lacking serum anti-DCN immunoreactivity [anti-DCN $(-)$ ] ( post hoc Fisher's PLSD; ${ }^{*} p<0.03$; $\left.{ }^{* *} p<0.01 ;{ }^{* * *} p<0.005\right)$. Error bars indicate SE.

behavioral measurements. When control and GABHS mice were analyzed together $(n=20)$, a significant correlation was observed between the rank scores of DCN IgG deposits and rearing count (Spearman's Rho, 0.477; $p=0.0377$ ) (Fig. 6). Rank scores for DCN IgG deposits and ambulatory distance were not correlated. However, when control and GABHS mice were analyzed separately, rank scores for DCN IgG deposits in GABHS mice $(n=$ $10)$ were significantly correlated with both rearing count (Spearman's Rho, $0.700 ; p=0.0360$ ) and ambulatory distance (Spearman's Rho, $0.721 ; p=0.0305)$. In contrast, for control mice $(n=$ 10), rank scores for DCN IgG deposits were not correlated with either rearing count (Spearman's Rho, 0.006; $p=0.9855$ ) or ambulatory distance (Spearman's Rho, 0.455; $p=0.1727$ ).

Behavioral correlates of serum antibody responses to

GABHS immunization

To assess whether behavioral disturbances in our mouse model were correlated with immunity to specific bacterial proteins, we 
Table 1. Rearing counts are significantly correlated with other behavioral variables in dark-box, open-field, and hole-board tests

\begin{tabular}{|c|c|c|c|c|c|c|}
\hline \multirow[b]{2}{*}{ Behavioral variable } & \multicolumn{2}{|l|}{ Dark box } & \multicolumn{2}{|l|}{ Open field } & \multicolumn{2}{|l|}{ Hole board } \\
\hline & Control & GABHS & Control & GABHS & Control & GABHS \\
\hline Dark time & ns & ns & & & & \\
\hline Ambulatory distance & $\begin{aligned} r^{2} & =0.78 \\
p & =0.006\end{aligned}$ & $\begin{aligned} r^{2} & =0.62 \\
p & =0.055\end{aligned}$ & ns & $\begin{aligned} r^{2} & =0.68 \\
p & =0.028\end{aligned}$ & $\begin{aligned} r^{2} & =0.63 \\
p & =0.070\end{aligned}$ & $\begin{aligned} r^{2} & =0.71 \\
p & =0.018\end{aligned}$ \\
\hline Center time & $\begin{aligned} r^{2} & =0.620 \\
p & =0.0552\end{aligned}$ & ns & $\begin{aligned} r^{2} & =0.86 \\
p & =0.0006\end{aligned}$ & $\begin{aligned} r^{2} & =0.90 \\
p & =0.0001\end{aligned}$ & ns & ns \\
\hline Nose pokes & & & & & ns & ns \\
\hline
\end{tabular}

Measurements of several behavioral variables were recorded in dark-box, open-field, and hole-board tests using an automated system (see Materials and Methods). Z-test and Fisher's $r$ to $z$ transformation (Statview software) were used to determine significant correlations between rearing count and other behavioral variables. Correlation coefficients $\left(r^{2}\right)$ and corresponding $p$ values, where $p<0.1$, are presented; significant correlations are in bold.

profiled individual mouse sera in Western blots of GABHS homogenate. Sera obtained at the time of Trial 1 were used at dilutions of 1:250 and 1:2500. All 10 GABHS mouse sera were immunoreactive with GABHS at dilutions of 1:250 (data not shown)and 1:2500 (Fig. 7a). Although patterns were not consistent, anti-DCN $(+)$ sera were more reactive over the entire range of GABHS proteins than anti-DCN $(-)$ sera (Fig. $7 a$; asterisks correspond to anti-DCN $[+]$ sera). Serum from one control mouse had modest binding to GABHS at 1:250 dilution (data not shown).

We next examined the relationship between behavior and the magnitude of the anti-GABHS antibody response to GABHS immunization. $Z$ test and Fisher's $r$ to $z$ transformation were used to test for correlations of behavioral variables (trial 1 tests) with serum anti-GABHS immunoreactivity index. Control mice were not included in this analysis. Serum immunoreactivity to GABHS was correlated with rearing count in both open-field $\left(r^{2}=0.648\right.$; $p=0.0411)($ Fig. $7 b)$ and hole-board $\left(r^{2}=0.669 ; p=0.0325\right)$ tests and with move time in open-field $\left(r^{2}=0.790 ; p=0.0046\right)$ (Fig. $7 c$ ) and hole-board $\left(r^{2}=0.748 ; p=0.0103\right)$ tests. Other measures of ambulatory behavior in trial 1 open-field and holeboard tests correlated with serum immunoreactivity to GABHS included total distance, average velocity, ambulatory distance, and average distance per ambulatory movement (Table 2). Serum anti-GABHS immunoreactivity was not correlated with center time, behavioral measurements from the dark-box test, or exploratory nose pokes into the hole board (data not shown).

Within the GABHS-immunized group, there was a correlation between serum anti-GABHS immunoreactivity and ambulatory distance: mice that had high serum anti-GABHS immunoreactivity were most ambulatory (Fig. 7). However, group comparisons showed that ambulatory behavior in GABHSimmunized mice was decreased overall compared with control mice (Fig. 4) (mean ambulatory distance: GABHS, $1431 \mathrm{~cm} \pm$ 179 SD; controls, $1746 \mathrm{~cm} \pm 392$ SD; range: GABHS, 1214-1727 $\mathrm{cm}$; controls, 1339-2452 cm). Together, these results show that, although ambulatory behavior was decreased in the GABHS group as a whole, it was lowest in GABHS mice that had low serum antibody responses to GABHS immunization. When ambulatory distance in anti-DCN $(+)$, anti-DCN $(-)$, and control groups was compared, ANOVA showed a significant effect of group, with anti-DCN $(-)$ group showing the lowest mean ambulatory distance $[F=2.715 ; p=0.0393$; mean ambulatory distance (in $\mathrm{cm} \pm \mathrm{SD}$ ): control vs anti-DCN $(-)=1746 \pm 392 \mathrm{vs}$ $1263 \pm 41$; Fisher's PLSD, $p=0.0130$; control vs anti$\mathrm{DCN}(+)=1746 \pm 392$ vs $1544 \pm 136$; Fisher's PLSD, $p=\mathrm{ns}$; anti-DCN $(-)$ vs anti-DCN $(+)$; Fisher's PLSD, $p=n s]$.
To identify the antigen in brain tissue containing GABHS cross-reactive epitopes, normal mouse cerebellum was homogenized and analyzed by Western immunoblot using 10\% SDSPAGE. No specific immunoreactivity was observed with anti$\mathrm{DCN}(+)$ mouse sera (data not shown). To consider the possibility that conformational epitopes might be implicated, we next examined proteins extracted under nondenaturing conditions. One GABHS mouse serum was strongly immunoreactive in dot blot and nondenaturing Western blot analyses (Fig. 8a). Sera from control CFA:IFA-immunized mice were not reactive. Nondenaturing immunoprecipitations of normal mouse cerebellum were performed using sera from anti-DCN $(+)$ mouse immunoreactive in nondenaturing Western blots. After size fractionation on $12 \%$ polyacrylamide gels, proteins were excised and subjected to LC/MS/MS mass spectrometry (Fig. 8b). Two proteins were identified through this analysis: $\alpha-2$-macroglobulin and C4 complement.

\section{Discussion}

A broad spectrum of neuropsychiatric disorders is described in association with human GABHS infection, including SC, OCD, TS, and ADHD. Several lines of evidence suggest a role for humoral immunity in these disorders, including the presence of antineuronal antibodies (Husby et al., 1977; Kiessling et al., 1994; Singer et al., 1998; Wendlandt et al., 2001), clinical response to plasmapheresis or IVIg (Perlmutter et al., 1999), association of the disorder with the B cell marker D8/17 (Swedo et al., 1997), and the observation that intrastriatal injection of serum or IgG from subjects with TS elicits tic-like behavior in rats (Hallett et al., 2000; Taylor et al., 2002).

To investigate the role of immunity in the pathogenesis of GABHS-associated disease, we established a murine model on the basis of immunization with GABHS. GABHS mice had behavioral disturbances, serum antibodies that bound to specific brain regions, and IgG deposits in the brain. Immunolabeling was most prominent in DCN and colocalized in neuronal cell bodies with the synaptic marker SNAP-25. Labeling was present to a lesser degree in the thalamus and globus pallidus, brain regions representing elements of the CSTC loop thought to mediate PANDAS symptoms. GABHS mice were less ambulatory than controls; however, the subset of GABHS mice having serum anti-DCN antibodies exhibited increased rearing behavior during openfield and hole-board tests. The overall tendency toward hypoactivity observed in trial 1 in GABHS mice was most prominent in the subset that had low serum antibody responses to GABHS immunization. This may reflect differences between GABHS 
a


Figure 6. $\lg G$ deposits in the $D C N$ are associated with increased rearing behavior. Spearman's rank correlation test was performed to test for significant correlations between rank scores for DCN IgG deposits and rearing and ambulatory behaviors. Individual scores for behavioral variables were converted to ranked data. $a$, Rank score for rearing count plotted as a function of rank score for DCN IgG deposits. $b$, Rank score for ambulatory distance plotted as a function of rank score for DCN IgG deposits. Filled boxes denote individual control mice, and open boxes denote individual GABHS mice. Regression lines were calculated by Statview software. For all mice $(n=20)$, Spearman's rank correlation test showed that rank scores for IgG deposits were significantly correlated with rank scores for rearing count (Spearman's Rho $=$ $0.477 ; p=0.0377$ ) but not with rank scores for ambulatory distance. When control individuals were omitted from the analysis, however, there were significant correlations between rank scores for lgG deposits and both behavioral variables (rearing count: Spearman's Rho $=0.700$, $p=0.0360$; ambulatory distance: Spearman's Rho $=0.721, p=0.0305$; dotted lines represent regression lines for GABHS-immunized animals only).

subsets in postimmunization Th1/Th2 cytokine responses and their potential modulation of behavior. Rearing and ambulatory behavior in GABHS-immunized mice were correlated with quantitative measures of serum IgG immunoreactivity to Western blotted GABHS proteins and IgG deposits in the DCN. Although this study did not establish a causal relationship between serum anti-DCN antibodies and behavioral abnormalities, our results support the hypothesis that anti-GABHS antibodies crossreactive with brain may contribute to behavioral disturbances and provide a model system with which to further investigate the relationship between the immune response to GABHS and neuropsychiatric disorders.
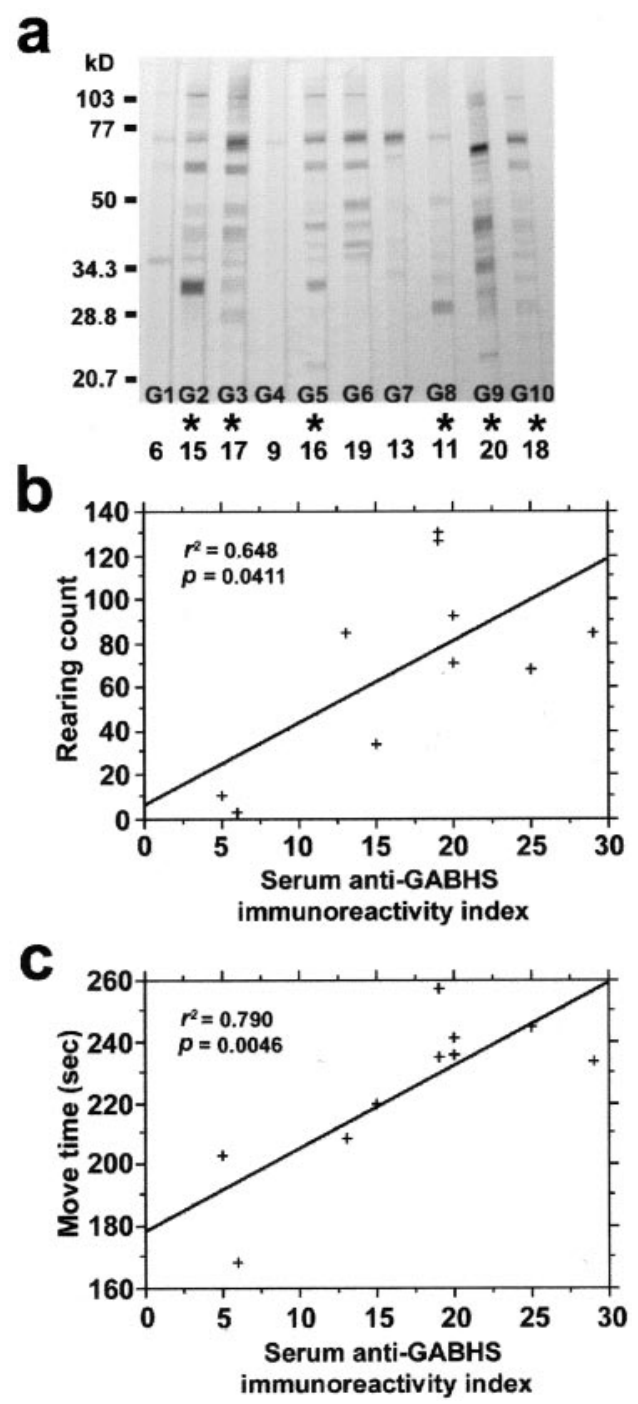

Figure 7. Sera from GABHS mice are immunoreactive to Western blotted GABHS proteins and correlate with behavior. Immunoblotting was performed on strips cut from Western blots of GABHS proteins resolved by SDS-PAGE, with sera from GABHS mice used as primary antisera. A $Z$ test and Fisher's $r$ to $z$ transformation were used to determine significant correlations between the magnitude of serum immunoreactivity to GABHS proteins (serum anti-GABHS immunoreactivity index; see Materials and Methods) and behavioral measurements. a, GABHS-immune sera from individual mice (designated G1-G10) at 1:2500 dilution. Asterisks indicate mice with serum anti-DCN immunoreactivity; individual rank score for DCN IgG deposits are shown below asterisks. $b, c$, Rearing count ( $b$ ) and move time ( $c$ ) from trial 1 open-field tests are plotted as a function of the serum anti-GABHS immunoreactivity index. Regression lines were calculated by Statview software. The serum anti-GABHS immunoreactivity index was significantly correlated with rearing count $\left(r^{2}=0.648 ; p=0.0411\right)$ and ambulatory distance $\left(r^{2}=0.790 ; p=\right.$ 0.0046 ). The presence of high serum anti-GABHS immunoreactivity was most often associated with serum anti-DCN immunoreactivity and a high rank score for lgG deposits in the DCN.

There is precedent for the observation that GABHS elicits antibodies cross-reactive to host proteins. Cross-reactive mouse monoclonal GABHS antibodies that bind to cytoskeletal and basement membrane proteins have been described previously (Cunningham, 2000). GABHS monoclonal antibodies that crossreact with $N$-acetyl- $\beta$-D-glucosamine (GlcNac), a component of GABHS and host carbohydrate, have also been found. Polyclonal antisera generated against GABHS proteins were found to be cross-reactive to unidentified components of human brain tissue 
Table 2. Behavioral variables are significantly correlated with serum anti-GABHS immunoreactivity

\begin{tabular}{lll}
\hline Behavioral variable & Open field & Hole board \\
\hline Distance & $r^{2}=0.75$ & $r^{2}=0.84$ \\
& $p=0.001$ & $p=0.001$ \\
Velocity & $r^{2}=0.76$ & $r^{2}=0.84$ \\
& $p=0.009$ & $p=0.001$ \\
Center time & $\mathrm{ns}$ & $\mathrm{ns}$ \\
Ambulatory distance & $\mathrm{ns}$ & $r^{2}=0.85$ \\
& & $p=0.0008$ \\
Average distance- & $r^{2}=0.64$ & $r^{2}=0.75$ \\
ambulatory movement & $p=0.045$ & $p=0.010$ \\
\hline
\end{tabular}

Measurements of several behavioral variables were obtained in open-field and hole-board tests using an automated system (see Materials and Methods). Z-test and Fisher's $r$ to $z$ transformation (Statview software) were used to determine significant correlations between the serum anti-GABHS immunoreactivity index (see Materials and Methods) and behavioral variables. Correlation coefficients $\left(r^{2}\right)$ and corresponding $p$ values are shown.

(Bronze and Dale, 1993). Our results indicate that cross-reactive antibodies in some GABHS mice bind to sequences found in $\mathrm{C} 4$ complement and $\alpha$-2-macroglobulin proteins in the cerebellum of normal mice. Regions of sequence homology contain thioester bonds (Isaac and Isenman, 1992) that are associated with function and sensitive to denaturing conditions (Sim and Sim, 1981, 1983). Deficiency of C4, a member of the $\alpha$-2-macroglobulin superfamily and a component of the classical pathway of complement activation, is associated with autoimmunity in mouse models of systemic lupus erythematosus (Paul et al., 2002) and in humans with the disease (Traustadottir et al., 2002). C4b also binds to a region on $\mathrm{C} 4 \mathrm{~b}$-binding protein that overlaps with the binding site for M-proteins, anti-phagocytosis factors of streptococcus. Antibodies to $\mathrm{C} 4$ protein generated in GABHS mice might lead to reduced $\mathrm{C} 4$, or $\mathrm{C} 4 \mathrm{~b}$ function, or dysregulation of complement pathways, increasing the susceptibility of these mice to autoimmune disorders. Complement regulation may also play a role in CNS response to inflammatory signals (Barnum, 2002). $\alpha$-2-macroglobulin, a large glycoprotein protease inhibitor activated in brain by monoamines, has complex effects on neurite growth through interactions with neurotrophins (Mori et al., 1991; Skornicka et al., 2002). Binding of $\alpha$-2-macroglobulin may play a role in the pathogenesis of streptococcus-related disease (Toppel et al., 2003). Whether molecules targeted by crossreactive immune responses in GABHS mice are relevant in human PANDAS remains to be determined.

Anti-GABHS antibodies labeled small structures that resemble synaptic varicosities (Fig. 2). Double-labeling experiments revealed colocalization of fluorescent signal from GABHS sera and the synaptic marker SNAP-25 (Fig. 1). The pattern and distribution of immunolabel for GABHS sera are similar to that observed using techniques that stain the perineuronal net, a specialized basement membrane that surrounds neuronal somata in several brain regions, including the DCN and brainstem nuclei (Celio and Blumcke, 1994; Seeger et al., 1994). Interestingly, perineuronal nets of the DCN are readily stained using lectins that bind to GlcNac (Brauer et al., 1984; Steindler and Cooper, 1986). Given the cross-reactivity of some GABHS antibodies to GlcNac, and the similarity in distribution of anti-DCN immunoreactivity and perineuronal nets, we speculate that the GABHS antibodies cross-reactive to DCN may bind to a glycoprotein associated with the perineuronal net.

Given the basal ganglia volume changes reported in the PANDAS subgroup of OCD (Giedd et al., 2000) and the positive correlation between increased putamen and globus pallidus vol-
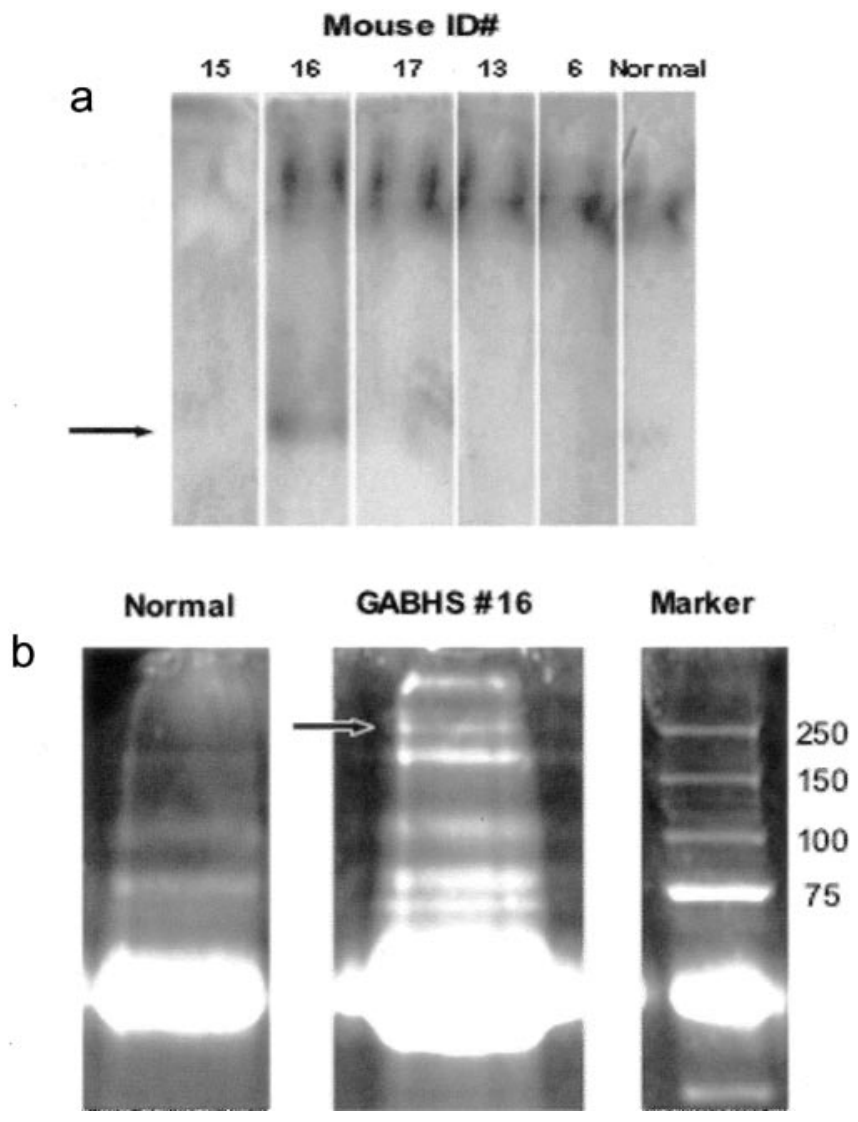

Figure 8. GABHS mouse sera binds to $\alpha$-2-macroglobulin and C4 complement in mouse cerebellum. $a$, Sera from mice immunized with GABHS were analyzed for binding to mouse cerebellar proteins in nondenaturing Western blots. $b$, Serum from a mouse with Ig $G$ deposits in DCN was used to precipitate protein from mouse cerebellum under nondenaturing conditions. Proteins were fractionated by 10\% PAGE and stained with Sypro Ruby. Bands in lane 2 were excised and analyzed by LC/MS/MS. Lane 1, Control IP with normal mouse sera; lane 2, IP with GABHS sera. The two bands indicated in lane 2 (arrow) correspond to $(4$ complement and $\alpha$-2-macroglobulin.

umes and serum GABHS antibodies in subjects with OCD and ADHD (Peterson et al., 2000), we predicted that GABHS mice would have antibodies cross-reactive with these brain regions. Some sera from GABHS mice were immunoreactive to globus pallidus and thalamus; however, the most striking immunoreactivity was to the DCN. In addition, despite the contribution of cerebellar regions during practicing of well learned motor skills, especially in the region of the deep cerebellar nuclei (Imamizu et al., 2000), the contributions of the cerebellum to behavior are not well recognized. Some PANDAS-OCD-TS imaging studies use the cerebellum as a reference point, precluding a direct assessment of its contributions, and most studies of immunoreactivity patterns of sera from OCD, TS, or SC patients have not examined immunoreactivity against cerebellum. Indeed, one study that included an assessment of immunoreactivity of cerebellum and cortex to streptococcal M-protein found reactivity against both cerebellum and cortex, although the most intense antibody reactions were observed with sections from basal ganglia (Bronze and Dale, 1993). Furthermore, several imaging studies that evaluated cerebellum in OCD (Kim et al., 2001; Kang et al., 2003) or the OCD spectrum disorder, trichotillomania (Swedo et al., 1991), report abnormalities in cerebellum at baseline or normalization 
in cerebellar regions after treatment. MRI studies have consistently shown decreased volumes in the posterior vermis of subjects with ADHD compared with control subjects (Mostofsky et al., 1998; Castellanos et al., 2001). Furthermore, children with autism, many of whom exhibit features of obsessive-compulsive disorder, have abnormalities in the cerebellum on MRI (Hardan et al., 2001).

We observed increased parenchymal anti-IgG immunolabeling in the DCN of GABHS mice. Although we interpret this observation as an indication of $\operatorname{IgG}$ accumulation that occurred in vivo, we cannot rule out the possibility that plasma IgG gained access to the brain parenchyma postmortem during tissue processing. However, the pericapillary distribution of IgG deposits is consistent with a model wherein anti-DCN antibodies in the periphery traverse the blood-brain barrier and bind to parenchymal targets in brain. Although plasma IgG does not typically cross to the brain, it can do so in the context of changes in the permeability of the blood-brain barrier seen in infection, exposure to foreign antigens, elevated cytokines or chemokines, or immunization with CFA and IFA (Rabchevsky et al., 1999; Chaudhuri, 2000). Additional support for a peripheral source of the IgG deposits comes from the lack of increase in the number of cells labeled with the panimmune cell marker CD45, although it is possible that immune cell infiltration was present at earlier time points and had resolved by the time of killing. The observation that IgG deposits were significantly correlated with altered behavior suggests the hypothesis that anti-DCN antibodies may be implicated in their pathogenesis, perhaps through activation of complement. Behavioral disturbances and local changes in catacholaminergic activity have been observed in rats after the introduction of immune complexes or the anaphylatoxin C5a into the hypothalamus (Schupf and Williams, 1985; Williams et al., 1985). Alternatively, binding of anti-brain antibodies to their target could directly interrupt the function of the target protein.

Behavioral alterations in GABHS mice varied according to the profile of the immune response to GABHS. Increased rearing behavior was associated with increased serum anti-DCN and anti-GABHS immunoreactivity and IgG deposits in the brain, whereas GABHS mice having lower serum anti-GABHS immunoreactivity were less ambulatory. We propose three potential explanations for these results. (1) Antibodies to GABHS antigens cross-react in a dose-dependent manner with neurotransmitter systems that modulate rearing behavior. Examples from other disorders in which cross-reactive antibodies are implicated include Rasmussen's encephalitis and stiff-person syndrome (Rogers et al., 1994; Whitney et al., 1999; Dalakas et al., 2000). (2) A robust antibody response to GABHS indicates bias toward a cytokine profile with physiological correlates that influence behavior. We do not have data on cytokine expression profiles in the GABHS model; however, there is precedent for cytokine-driven behavioral disturbances in mice (Zalcman et al., 1998; Zalcman, 2001, 2002), wherein peripheral administration of IL-1 caused reductions in locomotion and exploration of a novel open field, and IL- 2 and IL-6 promoted increased exploration, rearing, and locomotion. (3) Increased rearing behavior may be a correlate of an underlying genetic predisposition to specific immune responses to antigenic challenges. This last model is consistent with the reported increased frequency of previous diagnoses of neuropsychiatric disorders in subjects with acute RF (Mercadante et al., 2000).

Rearing in mice is considered to be a component of spatial orientation and exploration of novel surroundings. It is typically inhibited by anxiogenic circumstances and is modulated by monoaminergic systems. In novel surroundings, when there is motivation to return to the home cage, rearing presumably facilitates spatial orientation through improved visual and olfactory surveillance. Rearing is decreased by depleting brain dopamine (Hofele et al., 2001) and with benzodiazepines or 5-HT1A agonists (Tsuji et al., 2000). Rearing is increased by $\alpha$-2 adrenoreceptor antagonists (Delini-Stula, 1984) and dopamine D2 receptor agonists (Starr and Starr, 1986). In our study, increased rearing in control and GABHS mice was highly correlated with increased center time in open field and, to a lesser extent, with increased ambulation (Table 1). Rearing was not positively correlated with behaviors associated with increased anxiety, such as time spent in dark box, or thigmotaxis. Thus, increased rearing in GABHS mice may indicate a generalized behavioral disinhibition, in which exploratory behaviors normally expressed in response to a novel environment are facilitated. In mice with serum anti-DCN antibodies, however, rearing was increased independently of ambulatory distance and center time. This finding is consistent with rearing serving as an index to repetitive or compulsive rather than exploratory behavior.

We found significant correlations between measures for serum immunoreactivity to GABHS proteins, rearing count, and ambulatory behavior. The correlation in GABHS mice between IgG response to GABHS antigens and specific behaviors is intriguing in light of findings in human subjects with disorders associated with GABHS. Increased serum titers of antibodies to GABHS were associated with ADHD (Peterson et al., 2000) and TS (Muller et al., 2000, 2001). In GABHS mice, increased rearing behavior may reflect deficits in attention and disinhibited behavior similar to that seen in ADHD and TS.

Despite compelling similarities between the GABHS mouse and the human diseases it was designed to model, there are important caveats. Mice are not natural hosts for GABHS; thus, their immune response to GABHS antigens may differ from humans. Similarly, functional responses to brain injury may differ in mice and humans. Last, our mouse model is based on experimental immunization rather than natural infection. These differences notwithstanding, this model provides a starting point for investigations of the pathophysiology underlying motor and behavioral disturbances sometimes associated with an immune response to GABHS.

\section{References}

Asbahr FR, Negrao AB, Gentil V, Zanetta DM, da Paz JA, Marques-Dias MJ, Kiss MH (1998) Obsessive-compulsive and related symptoms in children and adolescents with rheumatic fever with and without chorea: a prospective 6-month study. Am J Psychiatry 155:1122-1124.

Barnum SR (2002) Complement in central nervous system inflammation. Immunol Res 26:7-13.

Brauer K, Bruckner G, Leibnitz L, Werner L (1984) Structural and cytochemical features of perineuronal glial nets in the rat brain. Acta Histochem 74:53-60.

Bronze MS, Dale JB (1993) Epitopes of streptococcal M proteins that evoke antibodies that cross-react with human brain. J Immunol 151:2820-2828.

Castellanos FX, Giedd JN, Berquin PC, Walter JM, Sharp W, Tran T, Vaituzis AC, Blumenthal JD, Nelson J, Bastain TM, Zijdenbos A, Evans AC, Rapoport JL (2001) Quantitative brain magnetic resonance imaging in girls with attention-deficit/hyperactivity disorder. Arch Gen Psychiatry 58:289-295.

Celio MR, Blumcke I (1994) Perineuronal nets-a specialized form of extracellular matrix in the adult nervous system. Brain Res Brain Res Rev 19:128-145. 
Chaudhuri JD (2000) Blood brain barrier and infection. Med Sci Monit 6:1213-1222.

Cunningham MW (2000) Pathogenesis of group A streptococcal infections. Clin Microbiol Rev 13:470-511.

Dalakas MC, Fujii M, Li M, McElroy B (2000) The clinical spectrum of anti-GAD antibody-positive patients with stiff-person syndrome. Neurology 55:1531-1535.

Delini-Stula A (1984) Simple behavioral measures of central alphaadrenoceptor blocking activity of drugs. Pol J Pharmacol Pharm 36:513-521.

Giedd JN, Rapoport JL, Garvey MA, Perlmutter S, Swedo SE (2000) MRI assessment of children with obsessive-compulsive disorder or tics associated with streptococcal infection. Am J Psychiatry 157:281-283.

Glass GV, Hopkins KD (1996) Statistical methods in education and psychology. Boston: Allyn and Bacon.

Hallett JJ, Harling-Berg CJ, Knopf PM, Stopa EG, Kiessling LS (2000) Antistriatal antibodies in Tourette syndrome cause neuronal dysfunction. J Neuroimmunol 111:195-202.

Hardan AY, Minshew NJ, Harenski K, Keshavan MS (2001) Posterior fossa magnetic resonance imaging in autism. J Am Acad Child Adolesc Psychiatry 40:666-672.

Hofele K, Sedelis M, Auburger GW, Morgan S, Huston JP, Schwarting RK (2001) Evidence for a dissociation between MPTP toxicity and tyrosinase activity based on congenic mouse strain susceptibility. Exp Neurol 168:116-122.

Husby G, v de Rijn I, Zabriskie JB, Ardin ZH, Williams Jr RC (1977) Antineuronal antibody in Sydenham's chorea. Lancet 1:1208.

Imamizu H, Miyauchi S, Tamada T, Sasaki Y, Takino R, Putz B, Yoshioka T, Kawato M (2000) Human cerebellar activity reflecting an acquired internal model of a new tool. Nature 403:192-195.

Isaac L, Isenman DE (1992) Structural requirements for thioester bond formation in human complement component C3. Reassessment of the role of thioester bond integrity on the conformation of C3. J Biol Chem 267:10062-10069.

Kang DH, Kwon JS, Kim JJ, Youn T, Park HJ, Kim MS, Lee DS, Lee MC (2003) Brain glucose metabolic changes associated with neuropsychological improvements after 4 months of treatment in patients with obsessive-compulsive disorder. Acta Psychiatr Scand 107:291-297.

Kiessling LS, Marcotte AC, Culpepper L (1994) Antineuronal antibodies: tics and obsessive-compulsive symptoms. J Dev Behav Pediatr 15:421-425.

Kim JJ, Lee MC, Kim J, Kim IY, Kim SI, Han MH, Chang KH, Kwon JS (2001) Grey matter abnormalities in obsessive-compulsive disorder: statistical parametric mapping of segmented magnetic resonance images. Br J Psychiatry 179:330-334.

Laemmli UK, Favre M (1973) Maturation of the head of bacteriophage T4. J Mol Biol 80:575-581.

Mercadante MT, Busatto GF, Lombroso PJ, Prado L, Rosario-Campos MC, do Valle R, Marques-Dias MJ, Kiss MH, Leckman JF, Miguel EC (2000) The psychiatric symptoms of rheumatic fever. Am J Psychiatry 157:2036-2038.

Mittleman BB, Castellanos FX, Jacobsen LK, Rapoport JL, Swedo SE, Shearer GM (1997) Cerebrospinal fluid cytokines in pediatric neuropsychiatric disease. J Immunol 159:2994-2999.

Moore DP (1996) Neuropsychiatric aspects of Sydenham's chorea: a comprehensive review. J Clin Psychiatry 57:407-414.

Mori T, Miyamoto Y, Iijima N, Kitabatake K, Kohsaka S (1991) Dissociation of neurite-promoting activity and protease-inhibiting function of alpha 2-macroglobulin in culture. Brain Res 567:355-357.

Mostofsky SH, Reiss AL, Lockhart P, Denckla MB (1998) Evaluation of cerebellar size in attention-deficit hyperactivity disorder. J Child Neurol 13:434-439.

Muller N, Riedel M, Straube A, Gunther W, Wilske B (2000) Increased antistreptococcal antibodies in patients with Tourette's syndrome. Psychiatry Res 94:43-49.

Muller N, Kroll B, Schwarz MJ, Riedel M, Straube A, Lutticken R, Reinert RR, Reineke T, Kuhnemund O (2001) Increased titers of antibodies against streptococcal M12 and M19 proteins in patients with Tourette's syndrome. Psychiatry Res 101:187-193.

Paul E, Pozdnyakova OO, Mitchell E, Carroll MC (2002) Anti-DNA autoreactivity in C4-deficient mice. Eur J Immunol 32:2672-2679.

Perlmutter SJ, Leitman SF, Garvey MA, Hamburger S, Feldman E, Leonard
HL, Swedo SE (1999) Therapeutic plasma exchange and intravenous immunoglobulin for obsessive-compulsive disorder and tic disorders in childhood. Lancet 354:1153-1158.

Peterson BS, Leckman JF, Tucker D, Scahill L, Staib L, Zhang H, King R, Cohen DJ, Gore JC, Lombroso P (2000) Preliminary findings of antistreptococcal antibody titers and basal ganglia volumes in tic, obsessivecompulsive, and attention deficit/hyperactivity disorders. Arch Gen Psychiatry 57:364-372.

Rabchevsky AG, Degos JD, Dreyfus PA (1999) Peripheral injections of Freund's adjuvant in mice provoke leakage of serum proteins through the blood-brain barrier without inducing reactive gliosis. Brain Res 832:84-96.

Rogers SW, Andrews PI, Gahring LC, Whisenand T, Cauley K, Crain B, Hughes TE, Heinemann SF, McNamara JO (1994) Autoantibodies to glutamate receptor GluR3 in Rasmussen's encephalitis. Science 265:648-651

Schupf N, Williams CA (1985) Effect of immune complex-forming reactants on catecholamine-modulated behaviors in the rat hypothalamus. J Neuroimmunol 9:13-27.

Seeger G, Brauer K, Hartig W, Bruckner G (1994) Mapping of perineuronal nets in the rat brain stained by colloidal iron hydroxide histochemistry and lectin cytochemistry. Neuroscience 58:371-388.

Sheppard DM, Bradshaw JL, Purcell R, Pantelis C (1999) Tourette's and comorbid syndromes: obsessive compulsive and attention deficit hyperactivity disorder. A common etiology? Clin Psychol Rev 19:531-552.

Sim RB, Sim E (1981) Autolytic fragmentation of complement components C3 and C4 under denaturing conditions, a property shared with alpha 2-macroglobulin. Biochem J 193:129-141.

Sim RB, Sim E (1983) Autolytic fragmentation of complement components C3 and C4 and its relationship to covalent binding activity. Ann NY Acad Sci 421:259-276.

Singer HS, Giuliano JD, Hansen BH, Hallett JJ, Laurino JP, Benson M, Kiessling LS (1998) Antibodies against human putamen in children with Tourette syndrome. Neurology 50:1618-1624.

Skornicka EL, Shi X, Koo PH (2002) Comparative binding of biotinylated neurotrophins to alpha(2)-macroglobulin family of proteins: relationship between cytokine-binding and neuro-modulatory activities of the macroglobulins. J Neurosci Res 67:346-353.

Starr BS, Starr MS (1986) Differential effects of dopamine D1 and D2 agonists and antagonists on velocity of movement, rearing and grooming in the mouse. Implications for the roles of D1 and D2 receptors. Neuropharmacology 25:455-463.

Steindler DA, Cooper NG (1986) Wheat germ agglutinin binding sites in the adult mouse cerebellum: light and electron microscopic studies. J Comp Neurol 249:170-185.

Swedo SE, Rapoport JL, Cheslow DL, Leonard HL, Ayoub EM, Hosier DM, Wald ER (1989) High prevalence of obsessive-compulsive symptoms in patients with Sydenham's chorea. Am J Psychiatry 146:246-249.

Swedo SE, Rapoport JL, Leonard HL, Schapiro MB, Rapoport SI, Grady CL (1991) Regional cerebral glucose metabolism of women with trichotillomania. Arch Gen Psychiatry 48:828-833.

Swedo SE, Leonard HL, Schapiro MB, Casey BJ, Mannheim GB, Lenane MC, Rettew DC (1993) Sydenham's chorea: physical and psychological symptoms of St Vitus dance. Pediatrics 91:706-713.

Swedo SE, Leonard HL, Mittleman BB, Allen AJ, Rapoport JL, Dow SP, Kanter ME, Chapman F, Zabriskie J (1997) Identification of children with pediatric autoimmune neuropsychiatric disorders associated with streptococcal infections by a marker associated with rheumatic fever. Am J Psychiatry 154:110-112.

Swedo SE, Leonard HL, Garvey M, Mittleman B, Allen AJ, Perlmutter S, Lougee L, Dow S, Zamkoff J, Dubbert BK (1998) Pediatric autoimmune neuropsychiatric disorders associated with streptococcal infections: clinical description of the first 50 cases. Am J Psychiatry 155:264-271.

Taylor JR, Morshed SA, Parveen S, Mercadante MT, Scahill L, Peterson BS, King RA, Leckman JF, Lombroso PJ (2002) An animal model of Tourette's syndrome. Am J Psychiatry 159:657-660.

Toppel AW, Rasmussen M, Rohde M, Medina E, Chhatwal GS (2003) Contribution of protein G-related alpha2-macroglobulin-binding protein to bacterial virulence in a mouse skin model of group A streptococcal infection. J Infect Dis 187:1694-1703. 
Traustadottir KH, Sigfusson A, Steinsson K, Erlendsson K (2002) C4A deficiency and elevated level of immune complexes: the mechanism behind increased susceptibility to systemic lupus erythematosus. J Rheumatol 29:2359-2366.

Tsuji M, Takeda H, Matsumiya T (2000) Different effects of 5-HT1A receptor agonists and benzodiazepine anxiolytics on the emotional state of naive and stressed mice: a study using the hole-board test. Psychopharmacology (Berl) 152:157-166.

Wendlandt JT, Grus FH, Hansen BH, Singer HS (2001) Striatal antibodies in children with Tourette's syndrome: multivariate discriminant analysis of IgG repertoires. J Neuroimmunol 119:106-113.

Whitney KD, Andrews PI, McNamara JO (1999) Immunoglobulin G and complement immunoreactivity in the cerebral cortex of patients with Rasmussen's encephalitis. Neurology 53:699-708.

Williams CA, Schupf N, Hugli TE (1985) Anaphylatoxin C5a modulation of an alpha-adrenergic receptor system in the rat hypothalamus. J Neuroimmunol 9:29-40.

Zalcman SS (2001) Interleukin-2 potentiates novelty- and GBR 12909induced exploratory activity. Brain Res 899:1-9.

Zalcman SS (2002) Interleukin-2-induced increases in climbing behavior: inhibition by dopamine D-1 and D-2 receptor antagonists. Brain Res 944:157-164.

Zalcman S, Murray L, Dyck DG, Greenberg AH, Nance DM (1998) Interleukin-2 and -6 induce behavioral-activating effects in mice. Brain Res 811:111-121. 